\title{
Closure of Artisanal Small Scale Gold Mining Processing Plants in Ecuador
}

\author{
Brandon Nichols ${ }^{1}$, Marcello Veiga ${ }^{1}$, Dirk van $Z^{2} 1^{1}$ \& Andre Moura Xavier ${ }^{1}$ \\ ${ }^{1}$ Norman B. Keevil Institute of Mining Engineering, University of British Columbia, Canada \\ Correspondence: Andre Moura Xavier, Norman B. Keevil Institute of Mining Engineering, University of British \\ Columbia, Canada. E-mail: andmox2003@gmail.com
}

Received: February 11, 2015 Accepted: March 3, 2015 Online Published: May 31, 2015

doi:10.5539/jms.v5n2p41 URL: http://dx.doi.org/10.5539/jms.v5n2p41

\begin{abstract}
Political tension over the discharge of artisanal mine tailings into the Puyango-Tumbes River in Ecuador, which flows into northern Peru, has prompted the closure of the responsible artisanal small gold processing plants and the construction of central processing and communal tailings facility. A coordinated effort on behalf of the federal government, miners, and the local community to develop and fund the project and bring it to completion is underway with the goal of eliminating riverine tailings disposal in the area and reclaiming the current artisanal gold processing plants. The authors propose that any approach to closure planning of ASGM must be: (1) economic and feasible to the community and miners, (2) reasonable for individuals in the community to implement on their own, and (3) expedient, as the process may not follow conventional closure techniques but instead be adapted to function within the ASGM context. The goal of this paper is to reflect on the closure process developed for the artisanal gold processing plants, their dismantlement and reclamation.
\end{abstract}

Keywords: mine closure, mercury contamination, artisanal mining

\section{Context}

For over two decades, artisanal small-scale gold miners (ASGM) have operated mineral processing plants along the Calera and Amarillo Rivers near Portovelo, Ecuador. These processing plants have discharged tailings containing mercury, cyanide, and arsenic into these rivers, the flows of which join the Puyango-Tumbes River and flow into Peru (Tarras-Wahlberg, 2002). The waste dischargehas devastated aquatic life for $160 \mathrm{~km}$ downstream, creating an international dispute between Ecuador and Peru over the ecological damage and health effects, estimated to be up to \$US 35 billion (PIMET, 2012; Tarras-Wahlberg, 2002). The Ecuadorian government has responded in cooperation with the InstitutoNacionalGeológicoMineroMetalúrgico del Ecuador (INIGEMM); the Association of Owners of Plantsof Ore Reduction, Smelting and Refining of Mineral Substances of El Oro Province (APROPLASMIN) in Portovelo-Zaruma; the University of Lojas; the University of British Columbia (UBC); and local municipalities to develop a closure plan for the current ASGM operations to be replaced bya central processing park (CPP) and a communal tailings facility (CTF) to store current and future mineral processing waste from the CPP (PIMET, 2012; Tarras-Wahlberg, 2002). The objective of this paper is to examine the current ASGM situation in Ecuador and to disucss the closure process developed for the ASGM plants, their dismantlement and reclamation.

\section{Artisanal Small Scale Mining (ASM)}

More than 30 million individuals engage in ASM operations worldwide, extracting more than 30 different minerals using rudimentary processes known to degrade the natural environment (Veiga et al., 2014). ASM operations are also commonly associated with negative social, economic, and cultural impacts for groups living near ASM operations (Hinton et al., 2003). Despite the negative aspects, it is estimated that, worldwide, more than 300 million individuals benefit directly and indirectly from ASM, as many spin-off services and industries, such as transportation, fuel, equipment, food, and utilities, serve this sector (Hinton et al., 2003).

The number of Artisanal Small Scale Gold Mining (ASGM) operations has increased dramatically over the last 15 years in direct correlation with the rise in gold price. The market value of gold, its process of extraction from accessible ore bodies, and liquidity make it an ideal commodity for virtually any individual to extract and sell (Swenson et al., 2011). As a result, roughly half the artisanal miners in the world-approximately 15 
million - mine for gold, and the majority use mercury to extract gold from rich ores (Veiga et al., 2006).

Today, ASGM activities are the largest source of anthropogenic mercury emissions in the world, totaling $37 \%$ of inorganic mercury emissions, and have increased steadily since 1995 (Veiga et al., 2014). In 2010, it was estimated that 1,960 tonnes of mercury were emitted annually into the air from all human activities, 727 tonnes of which resulted from ASGM activity (UNEP, 2013; Veiga et al., 2014). As operations increase, so will the number of abandoned facilities, most of which are contaminated with mercury, cyanide, and other chemicals used in the extraction process (Veiga \& Hinton, 2002).

The effects of ASGM operations on human health in the Portovelo-Zaruma area are extensive and far-reaching. It was estimated that in 2010, the ASGM practice of burning amalgams released 1.5 tonnes of mercury, $70 \%$ to the atmosphere and 30\% into the rivers via tailings (González-Carrasco et al., 2011). A 2010 air quality analyses of metallic atmospheric mercury showed within the town of Portovelo, atmospheric concentrations of metallic mercury average $574 \pm 72.28 \mathrm{ng} / \mathrm{m}^{3}$ and $3,699.5 \pm 1,807.6 \mathrm{ng} / \mathrm{m}^{3}$ in the processing centers known as El Pache (González-Carrasco et al., 2011). The maximum allowable inhalation standard of inorganic mercury, according to the Agency for Toxic Substances and Disease Registry (2010), is $200 \mathrm{ng} / \mathrm{m}^{3}$, half that of the concentrations found in the urban town center and many times less then that of the processing centers. Inhaled inorganic mercury enters the lungs and the blood stream; damages the nervous system, lungs, kidneys, and liver; and builds up in the brain (Veiga \& Baker, 2004). High mercury levels in the urine can indicate excessive exposure to mercuryvapor, which can derive symptoms such as tremors and erythrism (abnormal irritability) (Veiga and Baker, 2004).

The cycle of ASGM begins with the discovery of a deposit; workers migrate to the site, the local economy expands, the resource is depleted, the miners leave, and the economy shrinks (Veiga \& Hinton, 2002). The expansion of ASGM operations is often associated with the corrosion of moral values, as the newfound prosperity attracts prostitution, drugs, and alcohol to the area (Veiga \& Hinton, 2002). When ASGM operations come to a close, a wake of social and environmental destruction is left behind (Hinton et al., 2003). To reduce, mitigate, and stop the negative impacts of ASGM activities, training and education are critical to empower communities and miners to understand how appropriate mine closure may result in social, economic, environmental, and health benefits for the communities left behind after ASGM operations cease.

The gold rush in the Brazilian Amazon reached its apex in 1989, when it was estimated that as many as one million artisanal miners were extracting about 100 tonnes/a of gold in more than 2,000 mining sites (Feijão and Pinto, 1992). In the Tapajós region, the largest ASGM area in the world, the gold rush in the 1990s left behind 7.5 tonnes of mercury in more than $50,000 \mathrm{~m}^{2}$ of untreated tailings (Sousa \& Veiga, 2009). After the easily accessible gold was depleted, what were once mining villages became shantytowns, characterized by poor health quality, high levels of pollution, acute poverty, and limited employment opportunities (Veiga et al., 2014).

The depletion of an ore body is not controlled by ASGM, since no reserves are established and there are no technical and financial capabilities to extend operations using more sophisticated techniques (Hinton et al., 2003) The result is abandonment, leaving the openpits filled with water and mercury (Veiga, 1997). However, there are a few cases of successful reclamation of ASGM sites. Otchere et al. (2004) describe how the artisanal mining community of Alta Floresta in southern Brazil transformed 116 abandoned open pits ranging from 1,000 to $10,000 \mathrm{~m}^{2}$ into fish farms, employing 900 people. Similarly, in the Brazilian Amazon, 4,200 artisanal miners that participated in the UNIDO Global Mercury Project refilled and vegetated some of the 141 pits (Sousa \& Veiga, 2009).

Any approach to closure planning of ASGM must be: (1) economic and feasible to the community and miners, (2) reasonable for individuals in the community to implement on their own, and (3) expedient, as the process may not follow conventional closure techniques but instead be adapted to function within the ASGM world (Hinton et al., 2003). The closure plan is only viable when the mining community is not transient and has the technical and economic support to think beyond the immediate benefits of mining. Considering this context, leadership and vision are fundamental to initiate and maintain the closure process in mining towns. Furthermore, political will, support, and participation are critical. This holds true in the case of Portovelo-Zaruma, Ecuador, as described in this paper.

\section{Portovelo, Ecuador}

The region of Portovelo-Zaruma is home to the oldest and one of the most well known mining communities in Ecuador. Mining activity began in the early twentieth century, when the South American Development Company, SADCO, developed the Portovelo gold deposit, operating it until closure in 1950 (Tarras-Wahlberg et al., 2001). Unused until 1984, the abandoned SADCO mine was invaded by artisanal miners who have developed their 
operations throughout the province of El Oro, in southern Ecuador (Tarras-Wahlberg et al., 2001).

Artisanal miners use explosives and hand tools to extract underground sulfide-rich quartz ore and to crush, grind and recover gold using gravity concentration methods (Tarras-Wahlberg et al., 2001). In 1999, it was estimated that 400 mines existed in the Portovelo-Zaruma region, serviced by 66 processing plants (Tarras-Wahlberg et al., 2001). Today, 87 gold processing facilities line the banks of the Puyango-Tumbes River, reportedly processing 3,000 tonnes of ore per day and producing nine tonnes of gold per year according to APROPLASMIN (Veiga et al., 2014). Each of those plants processes gold using one or a combination of mercury amalgamation and/or cyanidation, resulting in 0.65 tonnes of mercury and 6,000 tonnes of cyanide entering the watershed per year (Guimarães et al., 2011). The tailings are carried along the Tumbes River into Peru before entering the Pacific Ocean. Using isotopic methods, Adler-Miserendino (2012) suggested that the mercury in the sediment in the delta of the Puyango-Tumbes River, in Peru, originates in Portovelo, Ecuador. This shared pollution has created an international conflict between the two countries. To deal with this problem, the Ecuadorian government has decided to close the ASGM processing plants along the river and move them to a CPP with a central tailings storage facility (PIMET, 2012).

The proliferation of processing centers began in the early 1990s, when private holders provided for-rent mineral ore processing to miners who lacked the capital to build their own plants (Velásquez-López et al., 2010). Miners pay a nominal fee to crush their ore, concentrate it, and finally extract the gold using mercury amalgamation to recover $30-40 \%$ of the gold in the ore (Veiga et al., 2010). The remaining gold in the tailings is later extracted by the processing plant owner in agitation tanks with cyanide (Veiga et al., 2010). The ASGM sector directly supports 10,000 people in the Portovelo-Zaruma region and produces nine tonnes of gold each year (Veiga et al., 2010).

Ore processing using mercury combined with cyanidation and improper tailings management have resulted in a significant impact on the environment. Mercury concentrations in the sediments of the Calera River, which is downstream from ASGM processing centers, ranged between 1 and $5 \mathrm{mg} / \mathrm{kg}$; elevated levels of mercury have also been found in bottom-dwelling invertebrates, which is likely a result of decades of mercury deposition into the Calera River from processing facilities (Velásquez-López et al., 2010).

The majority of the processing facilities in the Portovelo-Zaruma region are built along or near the banks of the Puyango-Tumbes River. The river passes through a narrow valley that limits suitable locations for the 87 processing plants to dispose of their tailings. On average, each processing center processes 55 tonnes of ore per day, totaling 2,275 tonnes/day in the whole region. Site observation suggests the majority of the processing centers lack storage capacity for daily tailings production, the majority of which enters the Calera and Amarillo Rivers.

To prevent future tailings runoff entering the river, the Ecuadorian government, Instituto Nacional Geológico Minero Metalúrgico del Ecuador (INIGEMM), APROPLASMIN, and the local municipality are working together to create a closure program for the current processing centers. A migration plan to a new processing center and the construction of a communal tailings facility, El Tablón, to prevent the future tailings from escaping into the local watershed are underway.

\section{ASGM Processing Plants Closure}

In large-scale mining, mine closure planning is intended to protect public health and safety; to avoid, mitigate,and preferably eliminate all environmental impacts; to reclaim and reuse the land; and to ensure the structure of the social and economic fabric of the community are maintained postclosure (Xavier, 2013). Mines can close for several reasons, including: equipment failures; geotechnical, geological economic, regulatory, or government policy changes. Furthermore community opposition can also result in the closure of a mine (Laurence, 2006). ASGM closures can occur for the same reasons, but also may result from expulsion from the site by police or military, or seasonal and climatic changes.

In the case of the ASGM operations in Portovelo-Zaruma, closure of the current facilities is in response to a potential lawsuit of up to \$US 35 billion dollars from the Peruvian government, which is claiming damages for the harmful effects of the Ecuadorian ASGM operations; regulatory changes to improve environmental standards within Ecuador; and local community pressure by those who have been affected by the ASGM operations (PIMET, 2012).

A unique opportunity to observe the development of an ASGM closure plan in conjunction with the construction of a communal tailings facility has been developing in Portovelo, Ecuador. In April 2013, a research team from the Norman B. Keevil Institute of Mining Engineering of the University of British Columbia surveyed 52 of the 
87 processing facilities in the Portovelo-Zaruma area with a 63-question survey investigating the current industrial, social, environmental, and economic conditions of ASGM processing plants and the community.

\section{ParqueMinero Industrial El Tablón (PIMET) (Note 1)}

Over the past two decades, mine tailings effluent from Ecuadorian ASGM operations were discharged into the Puyango-Tumbes watershed, contaminating the watershed, passing into Peru, and causing economic, social, and health issues for the people living downstream. Recognizing the severity of the Ecuador Puyango-Tumbes watershed destruction and the political and economic implications of not taking immediate and effective measures, the Ecuadorian government collaborated with local governments, APROPLASMIN, the University of British Columbia, and the Portovelo-Zaruma community to develop a new model of ASGM practice. Through the development of a central processing plant (CPP) and communal tailings facility (CTF), the approach is meant to mitigate and eliminate current environmental conflict with Peru (PIMET, 2012).

The CPP and CTF are being constructed south of Portovelo and were scheduled to be completed at the end of 2013, but construction has stretched into 2014 (PIMET, 2012). For a nominal fee, miners will have access to 150 Chilean mills and accompanying sluice boxes to process ore and recover gold (PIMET, 2012). The collected tailings from the Chilean mills will be processed by a central PIMET-operated flotation circuit to recover the remaining $\sim 40 \%$ gold, silver, and copper as a concentrate (PIMET, 2012). The final tailings product will be deposited in the PIMET-operated tailings facility.

In addition to constructing the CPP and CTF, the federal government has committed to building roads, bridges, and all other supporting infrastructure required for the success of the project (PIMET, 2012). During the construction phase, new environmental regulations from Ecuador's Ministry of the Environment and INIGEMM will require all tailings to be confined, banning all riverine tailings disposal as of the first quarter of 2013 (PIMET, 2012). Currently, 68 of the 87 operating plants have applied to comply with the project's environmental protocols, of which 57 have met the requirements set forth; the remainder will be suspended (PIMET, 2012).

Post closure, the existing tailings ponds will need to be transferred to the CTF. It was decided that current tailings would be moved to the CTF via a high-density polyurethane pipeline, rather then hauling the material through Portovelo by truck, which could put the community at risk if a spillage were to occur (PIMET, 2012) The pipeline runs along the Calera and Amarillo Rivers, where ASGM plants are located, joining at a pump station where the tailings are pumped up to the CTF. Designed with a maximum lifespan of 27 years, the CTF will store 290,000 tonnes of tailings per year over its life span, costing US\$ 670,000 per year or US\$2-3 per one of tailings stored (Tarras-Wahlberg, 2002).

The primary goal of the CTF is to contain all tailings produced by ASGM processes at the CPP. Together, these facilities stem tailings contamination in the Calera and Amarillo Rivers and effluents of the Puyango-Tumbes River that flows to Peru, localize ASGM activity, and provide proven technologies with which the ASGM community is familiar. The goals of this closure project are to ensure that (1) miners utilize the CPP; (2) all tailings are stored in the CTF; and (3) future ASGM activities do not reopen along the Calera and Amarillo Rivers. The latter would compromise the momentous efforts put forth by the government, the community, and the mining association (APROPLASMIN).

\section{General Composition of ASGM Processing Plants in Portovelo}

To prevent future ASGM start-ups outside of the CPP, complete closure, dismantlement of existing ASGM facilities, reclamation, and, ideally, repurposing of the land is mandatory. Accomplishing the closure of these facilities will require an audit of existing sites, equipment and infrastructure, the potential use of the land, and the presence of site contaminates, and gauging the scale of the remediation operations required to reclaim the land.

Typical ASGM operations in the region are based on the Chilean mill and sluice box. Chilean mills are the workhorses of the ASGM crushing and grinding circuit, consisting of two large, heavy wheels that traverse a circular metal track crushing ore shoveled manually. Chilean mills are constructed of half-plate steel, range in size from 2 to 3 meters in diameter and rest upon a concrete foundation based at the top of a concrete sluice box.

A typical sluice box is $6.8 \mathrm{~m}$ long by $0.46 \mathrm{~m}$ wide with two troughs imbedded within it, constructed of concrete declining by 5-6 degrees away from the Chilean mill. Depending on the site, the sluice may be $0.40 \mathrm{~m}$ to $0.60 \mathrm{~m}$ above the ground on a concrete floor. The combined footprint of a Chilean mill and sluice is $40 \mathrm{~m}^{2}, 34$ of the 52 processing facilities surveyed are using these to process ore. Using information complied from a UBC survey and field observations, Table 1 describes three average processing plants, the estimated size of the model sites, and the estimated amount of material — concrete and topsoil only - that needs to be removed. Buildings and roads are not included in these calculations, as they vary from site to site and could be reused if decontaminated. 
Table 1. Estimated average ASGM processing plant sizes and the estimatedconcrete and topsoil to be reclaimed on each site

\begin{tabular}{|c|c|c|c|c|c|c|}
\hline Plant size & \# ofmills\&sluices & Est. site size $\left(\mathrm{m}^{2}\right)$ & Concrete waste $\left(\mathrm{m}^{3}\right)$ & $\begin{array}{l}\text { Contaminated } \\
\text { topsoil }\left(\mathrm{m}^{3}\right)\end{array}$ & Number of sites & Total disposal $\left(\mathrm{m}^{3}\right)$ \\
\hline Large & 8 & 5,500 & 190 & 2,750 & 8 & 23,520 \\
\hline Medium & 5 & 4,250 & 120 & 2,125 & 13 & 29,185 \\
\hline Small & 3 & 3,000 & 70 & 1,500 & 15 & 23,550 \\
\hline Total & 44 & 102,265 & 4,130 & 72,125 & 36 & 76,255 \\
\hline
\end{tabular}

Dismantling the $4,054 \mathrm{~m}^{3}$ of concrete used to construct sluices and Chilean mill foundations, cleaning it of contaminates, and disposing of it is a significant hurdle that will require a great deal of resources. Due to the processes and chemicals used in ASGM operations - cyanide, mercury, nitric acid, bleach, gasoline, alcohol, hydrogen peroxide, oil, and diesel - a plan must be developed to deal with the contaminated topsoil and materials on site. The above estimates for topsoil removal account for half the site area, one meter deep. Mercury and cyanide were used in ASGM for more than 20 years in the area (Velásquez-López et al., 2010); to reclaim the area, it must be free of the above-listed materials and re-landscaped to ensure positive drainage. The purpose of this is two-fold: to remove all incentives for future ASGM projects from developing in the area, and to maximize the potential for other projects - industrial, residential, or other-to successfully develop on the old ASGM sites.

The resources required to reclaim the ASGM sites are substantial, as is the volume of material requiring cleaning and disposal. There are three potential outcomes for the future of the ASGM sites:(1) the sites are completely reclaimed and repurposed, and no ASGM activities return;(2) the sites are partially reclaimed, leaving partial ASGM infrastructure intact with limited potential for new industries to move in and the option for ASGM operations to restart easily; and (3) the sites are left as they are with most of the infrastructure in place, providing ample opportunity for ASGM operations to begin again.

\section{Results of Closing ASGM Processing Plants}

\subsection{Human Health}

Closure of ASGM processing plants and the ceasing of riverine tailings disposal will have two major health effect outcomes. First, eliminating mercury and cyanide discharge in the Calera and Amarillo Rivers will allow the downstream aquatic ecosystem to recover. Undestroyed cyanide is responsible for killing invertebrates and fish in the Calera River as well as severally impacting the Amarillo River (Tarras-Wahlberg, 2002). Preventing tailings from entering the river will have an immediate effect, bringing life back to the river, but persistent elements such as inorganic mercury will remain in the ecosystem; in the absence of high cyanide, these may become methylated as bacteria reestablish the river sediments (Veiga et al., 2014). This could have a negative effect on those who consume fish downstream of the processing plants, increasing their exposure to methylmercury as it biomagnifies up the ecosystem (Veiga et al., 2010). The second health closure outcome will be reduced exposure to mercury emissions from the processing plant, which is located farther from Portovelo and away from the general public. The establishment of the CPP also presents a new opportunity to reduce mercury use through education, supervision, and the purchase of gold-silver-copper concentrates over semi-refined gold doré made through the process of mercury amalgamation.

\subsection{Land Reclamation and Reuse}

Repurposing the land currently used by ASGM operations has the potential to allow new industries to move into the area and decrease the risk of future ASGM operations along the river. The more infrastructure that is left in place, the larger the incentive for ASGM operators to restart operations. To prevent this, the Ecuadorian government, the local community, and miners will need to strike a balance between the costs of completely reclaiming the ASGM sites and preventing future operations against the costs of permitting, monitoring, and policing those locations and others along the river. Failure to control the development of ASGM activities may result in further discharge of cyanide- and mercury-contaminated tailings into the river system, potentially degrading the international relations between Ecuador and Peru.

\subsection{Socio-Economic}

Replacing 87 privately owned autonomous mineral processing plants dispersed across the Portovelo-Zaruma region with one large central plant that provides three times the current processing capacity will change how the mining industry operates in the region, providing ample room for growth. Supporting industries will also have to 
migrate and potentially face heavy competition in the newly confined grounds of the CPP.

Gold recovery technology at the CPP will not be upgraded from the previous processing. The designers chose to stick with proven, familiar technologies to maintain confidence in the CPP among the ASGM processors who will rent the facility. This will result in no change to the equivalent gold extraction rates between the old processing plants and the new CPP, leaving ASGM incomes relatively constant.

The centralization process may also increase the density of miners at the new facility, creating new social dynamic and potentially exacerbating known social issues such as crime, prostitution, and drug and alcohol use (Veiga \& Hinton, 2002).

\subsection{Environmental}

Preventing the seepage of tailings into the Puyango-Tumbes River is the first step to recovering the waterways in the region, followed by programs to ensure new plants do not start up. Environmental monitoring pre and post closure to gauge the effectiveness of the program will be beneficial to future programs in which closure expenses are weighed against the health of the environment. Recording the levels of free cyanide, inorganic mercury, and methylmercury along the $160 \mathrm{~km}$ of effected waterways will provide invaluable data for future projects and models of the fates of these chemicals in the environment.

The reestablishment of wildlife within the Puyango-Tumbes River system will take time, recovering as free cyanide levels decrease (Gacsi et al., 2005). Unfortunately, high levels of organic mercury, which bacteria can transform into methylmercury, a persistent neurotoxin and well known bioaccumulator, will be present in the river system and readily build up the food chain (Morel et al., 2014).

To ensure future ASGM operations at the CPP operate responsibly, the Ecuadorian government and APROPLASMIN need to develop protocols following the International Cyanide Management Code (http://www.cyanidecode.org) for transporting, handling, using, or disposing of cyanide. Establishing relevant protocols for ASGM operations that follow the International Cyanide Management Code is a major step to preventing future environmental degradation as well as promoting best practices among ASGM operators when it comes to working with cyanide.

\section{Conclusion}

The closure of the 87 processing facilities will result in significantly less, if not zero, ASGM-generated tailings entering the local river system, allowing the river to recover and, possibly, return to a state that predates the presence of mining, aside from the persistent mercury contamination. To do so will require continued cooperation between the central and municipal governments of Ecuador, APROPLASMIN, and the local community.

Considering the potential opportunities and negative socio-economic impacts that may result from the closure of the ASGM processing plants, INIGEMM, APROPLASMIN, and UBC have organized the first economic diversification and community development workshop that aims to discuss with both local artisanal miners and the general community of Portovelo-Zaruma topics related to local economic diversification.

Future closure plans for ASGM operations can benefit from the outcome of the Portovelo-Zaruma plants. It has taken more than a decade to organize, plan, and begin construction of the communal tailings facility, and it may take another decade to close and reclaim the current ASGM sites. As to the success of the closure, this will depend on the balance between monitoring and site reclamation achieved by the government and the mining community.

\section{References}

Adler-Miserendino, R. A. (2012). Tracing mercury pollution in aquatic ecosystems: Implications for public health. (Unpublished doctoral dissertation). Johns Hopkins University, Baltimore, MD.

Agency for Toxic Substances and Disease Registry (ATSDR). (2010). Minimal risk levels (MRLs) for hazardous substances. Retrieved from http://www.atsdr.cdc.gov/mrls/mrllist.asp

Counter, S. A., Buchanan, L. H., \& Ortega, F. (2006). Neurocognitive screening of mercury- exposed children of Andean gold miners. The International Journal of Occupational and Environmental Health, 12, 209-214. $\mathrm{http}: / / \mathrm{dx}$. doi.org/10.1179/oeh.2006.12.3.209

CuentasProvinciales de El Oro. (2006). Convenio de cooperacio'ninterinstitucional entre el Gobierno Provincial Autonomo de El Oro y la Universidad Te'cnica de Machala. El Oro, Ecuador.

Feijão, A. J., \& Pinto, J. A. (1992). Amazon and the gold saga of the 20th century. In L. Barbosa, A. L. Lobato, \& 
J. A. Drummond (Eds.), Garimpo, MeioAmbiente e SociedadeIndígenas (pp. 18-36). Niteroi, Brazil: EDUFF-Ed. Univ. Fluminense (in Portuguese).

Gacsi, M., Czegeny, I., Nagy, G., \& Banfalvi, G. (2005). Survival of fish upon removal of cyanide from water. Environmental Research, 97(3), 293-299. http://dx.doi.org/10.1016/j.envres.2004.03.007

González-Carrasco, V., Velasquez-Lopez, P. C., Olivero-Verbel, J., \& Pájaro-Castro, N. (2011). Air mercury contamination in the gold mining town of Portovelo, Ecuador. Bulletin of Environmental Contamination and Toxicology, 87(3), 250-253. http://dx.doi.org/10.1007/s00128-011-0345-5

Guimarães, J. R. D., Betancourt, O., Miranda, M. R., Barriga, R., Cueva, E., \& Betancourt, S. (2011). Long-range effect of cyanide on mercury methylation in a gold mining area in southern Ecuador. Science of the Total Environment, 409, 5026-5033. http://dx.doi.org/10.1016/j.scitotenv.2011.08.021

Hinton, J. J., Veiga, M. M., \& Veiga, A. T. C. (2003). Clean artisanal gold mining: A utopian approach? Journal of Cleaner Production, 11(2), 99-115. http://dx.doi.org/10.1016/S0959-6526(02)00031-8

Laurence, D. (2006). Optimisation of the mine closure process. Journal of Cleaner Production, 14(3-4), 285-298. http://dx.doi.org/10.1016/j.jclepro.2004.04.011

Morel, F. M. M., Kraepiel, A. M. L., Amyot, M., \& Morel, F. M. M. (1998). The chemical cycle and bioaccumulation of mercury. Annual Review Ecology and Systematics, 29, 543-566. http://dx.doi.org/10.1146/annurev.ecolsys.29.1.543

Swenson, J. J., Carter, C. E., Domec, J.-C., \& Delgado, C. I. (2011). Gold mining in the Peruvian Amazon: Global prices, deforestation, and mercury imports. PloS One, 6(4), e18875. http://dx.doi.org/10.1371/journal.pone.0018875

Tarras-Wahlberg, N. H. (2002). Environmental management of small-scale and artisanal mining: The Portovelo-Zaruma goldmining area, southern Ecuador. Journal of Environmental Management, 65, 165-179. http://dx.doi.org/10.1006/jema.2002.0542

Tarras-Wahlberg, N. H., Flachier, A., Lane, S. N., \& Sangfors, O. (2001). Environmental impacts and metal exposure of aquatic ecosystems in rivers contaminated by small scale gold mining: The Puyango River Basin, southern Ecuador. The Science of the Total Environment, 278(1-3), 239-261. http://dx.doi.org/10.1016/S0048-9697(01)00655-6

Veiga, M. M. \& Hinton, J. J. (2002). Abandoned artisanal gold mines in the Brazilian Amazon: A legacy of mercury pollution. Natural Resources Forum, 26(1), 15-26. http://dx.doi.org/10.1111/1477-8947.00003

Veiga, M. M., Angeloci, G., Hitch, M., \& Colon Velásquez-López, P. (2014). Processing centres in artisanal gold mining. Journal of Cleaner Production, 64, 535-544. http://dx.doi.org/10.1016/j.jclepro.2013.08.015

Veiga, M. M., Maxson, P. A., \& Hylander, L. D. (2006). Origin and consumption of mercury in small-scale gold mining. Journal of Cleaner Production, 14(3-4), 436-447. http://dx.doi.org/10.1016/j.jclepro.2004.08.010

Velásquez-López, P. C., Veiga, M. M., \& Hall, K. (2010). Mercury balance in amalgamation in artisanal and small-scale gold mining: Identifying strategies for reducing environmental pollution in Portovelo-Zaruma, Ecuador. Journal of Cleaner Production, 18(3), 226-232. http://dx.doi.org/10.1016/j.jclepro.2009.10.010

Xavier, A. M. (2013). Socio-economic mine closure (SEMC) framework: A comprehensive approach for addressing the socio-economic challenges of mine closure. Retrieved from UBC, Electronic Thesis and Dissertations (2008+).

\section{Note}

Note 1. Industrial Mining Park—Plank.

\section{Copyrights}

Copyright for this article is retained by the author(s), with first publication rights granted to the journal.

This is an open-access article distributed under the terms and conditions of the Creative Commons Attribution license (http://creativecommons.org/licenses/by/3.0/). 